\title{
MOOCs, Emerging Technologies, and Quality
}

\author{
Libby V. Morris
}

Published online: 8 June 2013

(C) Springer Science+Business Media New York 2013

Daily, colleagues fill my email with articles about MOOCs (Massive Open Online Courses). The comments range from "intrigued" to "outraged" and are about as interesting as the articles. The most recent email shared news of a southern land-grant university that is planning to offer a MOOC.

Generally, I fall into the intrigued category; so much so that I recently spent time reading various news articles and blogs and visiting Coursera (https://www.coursera.org) and other MOOC websites to see what I could learn about the platform as there is very little research about this fast developing technological innovation. According to the Coursera website, 70 institutions are partners, including some of the most prestigious U.S. research universities, e.g., Yale, Michigan, Stanford, Minnesota, Florida, Virginia, University of North Carolina-Chapel Hill, and Georgia Institute of Technology, plus several international institutions. Courses are grouped by categories, and all are reported as free. Coursera features more than 40 people on their "team" so a business model is in place, but that is not my interest at this time.

Another MOOC provider is Harvard's edX where the slogan is "Take great courses from the world's best universities" https://www.edx.org/. As I write this editorial, a total of 51 courses are listed from 27 universities. Again, the names are mostly well known, e.g. Berkeley, MIT, University of Washington, and a few international participants. Peking University and McGill University are two examples of institutions outside the U.S.. The course titles at both sites represent the new and the traditional: "Globalization's Winners and Losers," "Comic Books and Graphic Novels," and "Introduction to Water Treatment." One can envision practicing professionals tackling work-related courses and other students, both young and old, sampling new areas of interest. In fact, I was tempted to enroll in a course to experience the format and to engage with topics not available during my formal education.

The criticisms of MOOCs are numerous: too many students, low interactivity, poor retention rates. Actually, the numbers of students enrolled in MOOCS are overwhelming. According to a New York Times article (Lewin, 2012), as early as fall 2011, Stanford had enrolled over 100,000 persons in a course on "Machine Learning;" and 13,000 persons completed the course, while "Introduction to Databases" enrolled over 90,000 and approximately 7,000 completed the course. With these numbers, questions about active learning, quality of the learning environment, and outcomes are numerous. Most articles on MOOCs suggest that the retention rate is low, generally less than $10 \%$, as illustrated by the numbers for the Stanford courses. The high dropout rate is attributed to both the educational environment and the administrative structure,

L. V. Morris $(\bowtie)$

Institute of Higher Education, University of Georgia, 102 Meigs Hall, Athens, GA 30602-6772, USA

e-mail: lvmorris@uga.edu 
i.e., mind boggling numbers, open enrollment, no investment to enroll, and the lack of academic credit for successful completion.

Udacity's homepage says, "Learn. Think. Do. Invent your future through free interactive college classes" (https://www.udacity.com). In collaboration with San Jose State University, however, a limited number of basic college credit-bearing courses are offered for a low fee. As my emails show each week, the range of collaborations and approaches to blended learning are growing rapidly as colleges experiment with ways to use technology to increase accessibility, retain students, and improve student performance (Lewin, 2013). There is no way to predict the future of instructional experiments like MOOCs, but I do not think they will just fade away.

There is a long history of individuals seeking independent study in this country at institutions offering higher education opportunities that are not place-bound. Early $20^{\text {th }}$ century courses in correspondence instruction endured for more than 100 years, and many transitioned successfully to online exchange of course materials, if not instructor-to-student interaction. Many students, especially mature employed and place bound adults, want and need alternatives to residential face-to-face instruction. Other students need enhanced instructional help to enter college or complete a degree. So, MOOCs are another platform, another technology, that will continue to morph as faculty members and students interact with and consider this emerging instructional tool.

It is noteworthy that a group of Harvard professors last week called for more oversight of Harvard's MOOCs offered through edX (Kolowich, 2013), recognizing that a radical transformation might be underway. So, for better or worse, higher education faculty members and administrators will need to consider carefully how the world of post-secondary education is changing around us and the possibilities and challenges posed by emerging technologies. With educational policy decisions replete with discussions of access and completion, instructional formats that seem to meet those overarching goals as well as student demand will continue to gain attention from a wide range of constituents (political, governmental, corporate). What we cannot sacrifice with these experiments and demands, however, are rigorous educational experiences that provide students with a quality education.

\section{References}

Kolowich, S. (2013, May 24). Harvard Professors Call for Greater Oversight of MOOCs. The Chronicle of Higher Education. Retrieved May 24, 2013 from http://chronicle.com/blogs/wiredcampus/harvard-professors-callfor-greater-oversight-of-moocs/43953?cid=pm\&utm_source=pm\&utm_medium=en

Lewin, T. (2012, March 4). Instruction for the Masses Knocks Down Campus Walls. The New York Times. Retrieved May 24, 2013 from http://www.nytimes.com/2012/03/05/education/moocs-large-courses-opento-all-topple-campus-walls.html?pagewanted=all

Lewin, T. (2013, April 30). Colleges Adapt Online Courses To Ease Burden. The New York Times, Retrieved May 24, 2013 from http:/query.nytimes.com/gst/fullpage.html?res=9E02E5D7163BF933A05757C0A9659D8B63\&ref= tamarlewin 